\title{
Attitudes and Perceptions of Health Care Practitioners Towards the Implementation of Integrating Mental Care into HIV Services At Primary Health Care Settings
}

\author{
Winnie Baphumelele Cele ${ }^{(\mathbb{D} *}$ and Euphemia Mbali Mhlongo \\ School of Nursing and Public Health, University of KwaZulu Natal, Durban, South Africa
}

\begin{abstract}
Background: The HIV infection and the use of antiretroviral drugs is associated with side effects which may lead to mental health disorders. Mental health challenges may cause exaggerated health outcomes and negatively affect patients' selfcare, leading to poor adherence to treatment.
\end{abstract}

Aim: The aim of this study was to determine the attitude and perception of health professionals towards implementing the integration of mental health care into HIV services at primary health care settings.

Methods: This was a quantitative, descriptive study. Purposive sampling method was employed to select health professional who participated in the study. Quantitative structured questionnaire was used to obtain information from the participants.

Results: Findings indicated that $57.5 \%$ of enrolled participants had a positive attitude and $72.5 \%$ had negative perception of the implementation of integrating mental health care into HIV services at primary health care settings.

Conclusion: There is need to integrate mental health into HIV services at primary health settings. Health professionals at primary health settings can be trained in regard to mental health as this may increase their level of competency and help boost their attitudes and perceptions to meet the mental health needs of patients.

Keywords

Primary health care, Mental health care, HIV services

\section{Introduction}

Globally, mental health problems have been established to be among the most common incapacitating health conditions. Mental health challenges most often occur alongside acute and chronic medical conditions and they have the potential to exaggerate associated health outcomes [1]. Ineffective mental health care is associated with the impairment of patient self-care as well as poor adherence to treatments and an increased rate of morbidity and mortality [2]. The burden of mental health problems is attributed, in part, to limited access to medical services and to chronicity of ailments. The problem of limited access in case of AIDS epidemic has become more salient to an extent. AIDS program expansion, in resource constraint settings, allows for integration of mental health care into HIV services $[3,4]$.

With improvement in HIV management, globally, mortality rates associated with AIDS epidemic has been largely brought under control [5]. This milestone has been achieved by using antiretroviral drugs. But health concerns still exist in the management of patients infected with HIV, several physical and neuropsychiatric disorders associated with disease continue to be the focus of health initiatives. It has been shown that mental health problems are high in people living with HIV, this may be as high as 50\% [5,6]. Depressive features are observed in a lot of HIV infected persons. In South Africa, about $25 \%$ of people living with HIV are believed to be affected by depression [7] and other common mental diseases are observed in about $50 \%$ of people infected with HIV [8].

* Corresponding author: Winnie Baphumelele Cele, Discipline of Nursing, School of Nursing and Public Health, University of KwaZulu-Natal, Durban, Private Bag X54001, Durban, 4000, South Africa

Accepted: July 21, 2021

Published online: July 23, 2021

Citation: Cele WB, Mhlongo EM (2021) Attitudes and Perceptions of Health Care Practitioners Towards the Implementation of Integrating Mental Care into HIV Services At Primary Health Care Settings. J Healthcare 4(1):70-76 
Citation: Cele WB, Mhlongo EM (2021) Attitudes and Perceptions of Health Care Practitioners Towards the Implementation of Integrating Mental Care into HIV Services At Primary Health Care Settings. J Healthcare 4(1):70-76

Misdiagnosis and underdiagnoses of mental health problems, regardless of high prevalence of mental ailments as well as psychiatric disorders in people living with HIV, are sources of concern [5]. The link between mental health disorders and HIV is complicated. Neurologic damage can be caused by HIV virus and opportunistic infections that are linked to AIDS $[9,10]$. Use of antiretroviral drugs is associated with side effects which may lead to mental health disorders. Mental ailments can negatively impact a patient's adherence to antiretroviral drugs, resulting in poor health outcomes [11]. This has led to extensive research and the development of strategic plans for the integration of HIV and noncommunicable diseases such as mental disorders $[9,12]$.

The benefits of mental health integration into already existing services, such as HIV services, in primary care settings include: high chances of providing holistic care, decreasing stigma associated with these conditions, and the availability and use of existing structures to enhance efficient patient care delivery [13]. In health sector, several practitioners are in support of making service delivery in primary care setting efficient in order to tackle both physical and behavioural medical conditions. This takes into recognition the allinclusive nature of services in primary care settings. It has also been observed that for many patients with behavioural challenges, primary health care centres are their first point of call [14].

Though there are obvious and indisputable benefits of integrating mental health into HIV services, problem of implementation still exist. In low- and middle-income countries, health care delivery systems are usually overloaded as result of meagre resources (human and financial), and such services are focused on treating just acute medical conditions. This leads to the fragmentation of care and diminished sustainability of health care for conditions that take a longer time to manage, like mental disorders and HIV infection $[15,16]$. In most cases, government funded mental health programs mainly focus on severe cases of mental disorders, which are only managed within the confines of specialist psychiatric hospitals, resulting in very little resources left to support mental health care in primary health care centres $[17,18]$.

This study was designed to determine attitudes and perceptions of health professionals towards implementing the integration of mental health into HIV services at primary health care level. This stems from knowledge that HIV infection, as well as use of antiretroviral drugs, may lend support to the development of adverse mental health conditions in HIV infected individuals and primary care centres are usually the first point of call for these patients $[9,19]$.

\section{Methods}

A descriptive quantitative design was used in this study. A total of 197 health professionals (mental health nurses, psychiatrists, psychologists, medical doctors), working in 3 selected health institutions completed the research instrument. The respondents were purposively selected. Data were collected from January 2018 to May 2018, and a structured questionnaire was used to explore attitudes and perceptions of health care practitioners towards the integration of mental health into HIV services in primary health care. The research instrument contained twenty four items, on a five point Likert scale, and the responses ranged from 1 = strongly disagree, 2 = disagree, 3 = neutral, $4=$ agree, and 5 = strongly agree. The Cronbach's alpha test was used to determine reliability of this study. A Cronbach's alpha score of $\geq 0.70$ was considered significant. Data was analysed using SPSS package Version 23.0. In this study, a p-value less than 0.05 was considered significant. One-way analysis of variance (ANOVA) was used to compare quantitative variables across groups. Continuous data was described using means and standard deviations while frequencies and percentages were used to describe categorical variables.

Study was approved by the Research Ethics Committee of the University of KwaZulu-Natal, protocol number: HSS/2248/017D. The study adhered to the ethical principles. Confidentiality and anonymity were maintained throughout the study.

\section{Results \\ Demographics}

Table 1 presents demographics of participants according to their qualifications. In this study, there was a total of $47.6 \%(n=90)$ mental health nurses, $30.4 \%(n=60)$ psychiatrists, $18.2 \%(n=36)$ medical doctors, and $5.6 \%(n$ $=11$ ) psychologists. The majority of participants were under the age of 45 years. Based on the number years of experience of all professionals enrolled in the study, it was noticed that in all four groups most participants fell in 2-5 years category, followed by those who come under 6-10 years category, and then $11-15$ years group.

\section{Attitudes of the participants}

The table above (Table 2) presents responses of health professionals on their attitude towards the implementation of integrating mental health into HIV services. It was observed that a significant percentage of participants, $82.5 \%$, believe, "it is important for any health professional supporting a person with a mental illness to also ensure that their physical health is assessed". Eighty seven percent agreed that they have a responsibility to intervene with people who have mental health challenges.

\section{Perceptions of participants}

Table 3 shows responses of health professionals on their perceptions towards implementing the integration of mental health into HIV services in primary health care. Sixty two point five percent (62.5\%) disagreed that people with mental health problems can never recover fully to live a quality life, $27.5 \%$ $(n=55)$ agreed that people with mental health problems can never recover fully to live a quality life. A number of health care professionals, about $57.5 \%(n=115)$, disagreed that integration of mental health care into HIV services can pose a danger to them, and $35 \%(n=110)$ agreed. Regarding treating people with mental health problems in HIV services, $40 \%$ agreed that it is a waste of time to treat people with mental health problems in HIV services and $52.5 \%(n=105)$ 
Citation: Cele WB, Mhlongo EM (2021) Attitudes and Perceptions of Health Care Practitioners Towards the Implementation of Integrating Mental Care into HIV Services At Primary Health Care Settings. J Healthcare 4(1):70-76

Table 1: Demographics across qualification of the participants $(\mathrm{N}=197)$.

\begin{tabular}{|c|c|c|c|c|c|}
\hline Demographics & $\begin{array}{c}\text { Mental Health Nurse. } \\
\text { n (\%) }\end{array}$ & $\begin{array}{l}\text { Psychiatrist. } \\
\text { n (\%) }\end{array}$ & $\begin{array}{c}\text { Psychologist. } \\
\text { n (\%) }\end{array}$ & $\begin{array}{l}\text { Medical doctor. } \\
\text { n (\%) }\end{array}$ & $\chi^{2}$ \\
\hline \multicolumn{6}{|l|}{ Gender } \\
\hline Female & $65(33.0)$ & $30(15.2)$ & $6(3.0)$ & $26(13.2)$ & \multirow{2}{*}{.026} \\
\hline Male & $25(12.7)$ & $30(15.2)$ & $5(2.5)$ & $10(5.1)$ & \\
\hline \multicolumn{6}{|l|}{ Age (years) } \\
\hline$\leq 25$ & $30(15.2)$ & $0(0.0)$ & $5(2.5)$ & $15(7.6)$ & \multirow{5}{*}{$<.0001$} \\
\hline 26-35 & $15(7.6)$ & $30(15.2)$ & $6(3.0)$ & $11(5.6)$ & \\
\hline $36-45$ & $10(5.1)$ & $20(10.2)$ & $0(0.0)$ & $5(2.5)$ & \\
\hline 46-55 & $25(12.7)$ & $5(2.5)$ & $0(0.0)$ & $0(0.0)$ & \\
\hline $56-65$ & $10(5.1)$ & $5(2.5)$ & $0(0.0)$ & $5(2.5)$ & \\
\hline \multicolumn{6}{|c|}{ Number of years in service as a mental health care professional (years) } \\
\hline $2-5$ & $35(19.2)$ & $20(11.0)$ & $5(2.7)$ & $20(11.0)$ & \multirow{5}{*}{$<.0001$} \\
\hline $6-10$ & $20(11.0)$ & $15(8.2)$ & $1(0.5)$ & 6. (3.3) & \\
\hline 11-15 & $15(8.2)$ & $10(5.5)$ & $5(2.7)$ & $0(0.0)$ & \\
\hline $16-20$ & $5(2.7)$ & $10(5.5)$ & $0(0.0)$ & $0(0.0)$ & \\
\hline$>20$ & $10(5.5)$ & $8(2.7)$ & $0(0.0)$ & $0(0.0)$ & \\
\hline \multicolumn{6}{|c|}{ Number of years in service as a health care professional working in HIV services (years) } \\
\hline $2-5$ & $45(29.8)$ & 30 (19.9) & $5(3.3)$ & $20(13.2)$ & \multirow{4}{*}{$<.0001$} \\
\hline 6-10 & $5(3.3)$ & $15(9.9)$ & $1(0.7)$ & $5(3.3)$ & \\
\hline 11-15 & $15(9.9)$ & $0(0.0)$ & $0(0.0)$ & $0(0.0)$ & \\
\hline $16-20$ & $0(0.0)$ & $5(3.3)$ & $5(3.3)$ & $0(0.0)$ & \\
\hline \multicolumn{6}{|c|}{ Number of years in service working as a primary health care professional at primary health care settings (years) } \\
\hline $2-5$ & $30(15.2)$ & $20(10.2)$ & $5(2.5)$ & $10(5.1)$ & \multirow{5}{*}{$<.0001$} \\
\hline 6-10 & $20(10.2)$ & $26(13.2)$ & $1(0.5)$ & $2(1.0)$ & \\
\hline 11-15 & $19(9.6)$ & $1(0.5)$ & $0(0.0)$ & $8(4.1)$ & \\
\hline $16-20$ & $16(8.1)$ & $13(6.6)$ & $0(0.0)$ & $16(8.1)$ & \\
\hline$>20$ & $5(2.5)$ & $0(0.0)$ & $5(2.5)$ & $0(0.0)$ & \\
\hline
\end{tabular}

*values presented as frequency (percentage).

Table 2: Participants attitude towards integrating mental health into HIV services at selected primary health care.

\begin{tabular}{|c|c|c|c|c|c|}
\hline \multirow[t]{2}{*}{ Items } & $\begin{array}{l}\text { Strongly } \\
\text { disagree }\end{array}$ & Disagree & Neutral & Agree & Strongly agree \\
\hline & N (\%) & N (\%) & N (\%) & N (\%) & N (\%) \\
\hline $\begin{array}{l}\text { It is important for any health professional supporting } \\
\text { a person with a mental Illness to also ensure that their } \\
\text { physical health is assessed. }\end{array}$ & $20(10.0)$ & $10(5.0)$ & $5(2.5)$ & 55 (27.5) & $110(55.0)$ \\
\hline $\begin{array}{l}\text { PHC nurses should not be expected to complete a } \\
\text { thorough assessment for people with mental health } \\
\text { symptoms because they can be referred to the } \\
\text { psychiatrist. }\end{array}$ & 35 (17.5) & 35 (17.5) & $15(7.5)$ & 55 (27.5) & $50(25.0)$ \\
\hline $\begin{array}{l}\text { I have a responsibility to identify people with mental } \\
\text { health problems. }\end{array}$ & $15(7.5)$ & $15(7.5)$ & $10(5.0)$ & $60(30.0)$ & $100(50.0)$ \\
\hline $\begin{array}{l}\text { I have a responsibility to intervene with people who } \\
\text { have mental health related problems. }\end{array}$ & $5(2.5)$ & $15(7.5)$ & $5(2.5)$ & 70 (35.0) & $105(52.5)$ \\
\hline $\begin{array}{l}\text { The significance of implementing the national mental } \\
\text { health policy framework on the integration of mental } \\
\text { health care into HIV services was explained to me. }\end{array}$ & $20(10.0)$ & $40(20.0)$ & $5(2.5)$ & 85 (42.5) & $50(25.0)$ \\
\hline
\end{tabular}

disagreed. Seventy two point five percent $(72.5 \% / \mathrm{n}=145)$ agreed that they have a responsibility to intervene with people who have mental health problems, however, $17.5 \%$ (n = 35) disagreed (Table 3).

Table 4 shows that $57.5 \%(n=115)$ of the participants had a positive attitude about implementing the integration of mental health into HIV services in primary health care. Only
$22.5 \%(n=45)$, of the participants had positive perceptions towards the implementation of integrating mental health into HIV services, while $72.5 \%(n=145)$ had negative perceptions.

\section{Group statistics}

A t-test and a series of ANOVA tests were performed to examine the differences in means with regards to attitude 
Citation: Cele WB, Mhlongo EM (2021) Attitudes and Perceptions of Health Care Practitioners Towards the Implementation of Integrating Mental Care into HIV Services At Primary Health Care Settings. J Healthcare 4(1):70-76

Table 3: Participants' responses on perceptions towards implementing the integration of mental health into HIV services in PHC.

\begin{tabular}{|c|c|c|c|c|c|}
\hline \multirow[t]{2}{*}{ Items } & $\begin{array}{l}\text { Strongly } \\
\text { disagree }\end{array}$ & Disagree & Neutral & Agree & Strongly agree \\
\hline & $\mathbf{N}(\%)$ & $\mathbf{N}(\%)$ & $\mathbf{N}(\%)$ & $\mathbf{N}(\%)$ & $\mathbf{N}(\%)$ \\
\hline $\begin{array}{l}\text { People with mental health problems can never } \\
\text { recover fully to live a quality life }\end{array}$ & $65(32.5)$ & $60(30.0)$ & $15(7.5)$ & $45(22.5)$ & $10(5.0)$ \\
\hline People with mental health problems are dangerous & $35(17.5)$ & $45(22.5)$ & $45(22.5)$ & $60(30.0)$ & $10(5.0)$ \\
\hline $\begin{array}{l}\text { Integration of mental health care into HIV services } \\
\text { can pose a danger to me }\end{array}$ & $55(27.5)$ & $60(30.0)$ & $15(7.5)$ & $30(15.0)$ & $40(20.0)$ \\
\hline $\begin{array}{l}\text { People with mental health problems should be } \\
\text { treated alone }\end{array}$ & $45(22.5)$ & $65(32.5)$ & $20(10.0)$ & $45(22.5)$ & $25(12.5)$ \\
\hline $\begin{array}{l}\text { It is a waste of time to treat people with mental } \\
\text { health problems in HIV services }\end{array}$ & $60(30.0)$ & $45(22.5)$ & $15(7.5)$ & $45(22.5)$ & $35(17.5)$ \\
\hline $\begin{array}{l}\text { I have a responsibility to intervene with people } \\
\text { who have mental health problems }\end{array}$ & $15(7.5)$ & $20(10.0)$ & $20(10.0)$ & $85(42.5)$ & $60(30.0)$ \\
\hline
\end{tabular}

Table 4: Attitude and perception score of participants.

\begin{tabular}{|l|c|c|c|}
\hline Attitude score & Frequency & Percentage & Mean \pm SD \\
\hline Positive attitude & 115 & 57.5 & \multirow{2}{*}{$10.60 \pm 3.20$} \\
\hline Negative attitude & 75 & 37.5 & \\
\hline Positive perception & 45 & 22.5 & \multirow{2}{*}{$18.82 \pm 5.91$} \\
\hline Negative perception & 145 & 72.5 & \\
\cline { 1 - 3 } & & &
\end{tabular}

and perception towards the implementation of integrating mental health care into HIV services. Table 4 shows that medical doctors had the most positive attitude (Mean $=12.39$ \pm 3.26 ), while participants aged between 56 and 65 years had the most positive perceptions (Mean $=25.33 \pm 2.58$ ). Those differences were statistically significant $(p=.000, .000$, and .000 respectively).

With regard to age, those aged 56 to 65 years had the most negative attitudes (Mean $=6.00 \pm 1.05$ ), and those aged 26 to 65 years had the most negative perceptions (Mean= $15.92 \pm$ $6.03)$. Those differences were significant $(p=.026, .000$, and .000 respectively). Statistical significance was also found with regards to gender, where females had more positive attitudes (Mean= 11.12 \pm 3.69$)$ and perceptions (Mean = $20.04 \pm 5.27$ ) than male $(p=.003$ and .000 respectively).

Concerning number of years' service as a mental health professional, the least experienced, those who had 10 years or less experience as mental health professional, had most positive attitudes (Mean $=11.55 \pm 3.40$ ). However, the most experienced mental health professionals had more positive perceptions (Mean $=24.67 \pm 1.95$ ). All those differences were statistically significant ( $p=.000, .000$, and .000 respectively). With regard to years of service working in HIV services, those who had 5 years or less had the most positive perceptions (Mean $=19.10 \pm 5.06)$. Those differences were significant ( $p=.000$ and .000 respectively). Results showed that those who had worked as primary health care professionals for more than 15 years had more positive perceptions than others (Mean $=21.11 \pm 4.15$ ). Those differences were found to be significant ( $p=.033$, and .001 respectively). Finally, medical doctors had a more positive attitude (Mean $=12.39$ \pm 3.26 ), and perception (Mean $=22.61 \pm 2.15$ ) than other professionals. Those differences were all significant $(p=.000$, .000 , and .000 respectively).

\section{Discussion}

The results obtained from this study show that the overall attitude of health professionals enrolled towards implementing the integration of mental health care into HIV at primary health care setting is quite commendable. More than an average number of participants enrolled in this study, $57.5 \%$, had positive attitudes about the implementation of integrating mental health care into HIV services (Table 4). Implementing integration of mental into HIV services will help to early diagnose mental disorders which are co-morbid with HIV infection, thus enabling the implementation of effective as well as robust intervention programmes. It is evident that this integration is needed, and it is practicable in low resource countries as well. Successful implementation of this integration will only be possible if all stakeholders are involved to make it a reality [12].

It was observed in this study that medical doctors had the most positive attitudes (Mean $=12.39 \pm 3.26$ ). We also found out that based on the number of years of service as a mental health care professional, the least experienced $\leq 10$ years working experience) had the most positive attitudes (Mean $=11.55 \pm 3.40$ ) towards the implementation of integrating mental health into HIV services $(p<0.05)$. From the responses obtained to questions about the study participants' attitudes, a majority of health professionals $(82.5 \%$ of participants agree) believe it is important for health professionals that are managing a person with mental illness to also make sure that the person's physical health is evaluated. The role played by HIV professionals in the diagnosis and management of mental illnesses is very important and is needed to increase the effectiveness of antiretroviral care and also and the adherence of patients to treatment regimens [7]. It is essential for a user friendly and comprehensive tool that serves as the foundation or basis for the management of patients with mental challenges at a primary health care level to be developed. This tool should be designed in a way that it will be easy to use by non-specialists [20]. Results from this study indicate that more than $52.5 \%$ of the participants do not support nurses at a primary health care level carrying out a complete and thorough assessment for people with mental health symptoms. This finding can be corroborated by a similar finding [7] which shows that there is perceived 
Citation: Cele WB, Mhlongo EM (2021) Attitudes and Perceptions of Health Care Practitioners Towards the Implementation of Integrating Mental Care into HIV Services At Primary Health Care Settings. J Healthcare 4(1):70-76

weakness in the diagnosis of mental ailments which may be due to a deficiency in the needed competency as well as inadequate resources for the screening of patients. These authors went further to state that nurses at primary health care levels should be trained in order to equip them with the basic skills needed to diagnose mental conditions [7].

It was observed that a great majority of the participants, $80 \%$, believe that they have a responsibility to identify people with mental health challenges. This result is in line with that of a similar study in Ethiopia where a significant number of the participants in that study indicated that mental health care is vital, and they showed an interest in delivery of mental care [21]. Also, in a similar study [22], a number of participants were in support of mental health assessments for HIV infected people. A great majority, $87.5 \%$, of participants responded positively that they have a responsibility to intervene with people who have mental health related problems.

It has been reported that it is essential to not only train HIV care workers on mental health management skills, but also to make sure these workers are willing to accept responsibility that comes with their job [22]. The level of exposure and training health professionals receive is an important factor that plays a crucial role in the delivery of mental care and also in the development of responsibility towards effective service delivery. Primary health care workers who have been exposed to pre-service clinical postings will have a better attitude towards mental care delivery [21].

Mental disorders pose a great global challenge that has led to an increase in interest by all the stakeholders involved around the globe to develop and evaluate policies that will enable countries to boost their capacity to tackle mental disorders [2,23-25]. Research has also revealed that primary health care is a key strategy needed for the provision of complete and holistic mental health care [24].

This study went further to determine the perceptions of participants towards implementing the integration of mental healthcare into HIV services. From the results obtained, it was observed that a great majority of participants, $72.5 \%$, had negative perceptions towards the implementation of mental health care integration into HIV services at the selected primary health care institutions (Table 4). This negative perception of health professionals, despite their positive attitudes to the integration of mental health into HIV services, may be because of their level of competence and expertise. It was reported in a study that service providers showed little confidence in their ability to screen, as well as manage, mental illness. These authors went on to say that the enrolled participants in their study favoured others doing the screening for mental disorders. This may be due their level of training, so they feel a more competent person should handle it [22]. The scarcity of well-trained medical professionals at a primary health care level in mental healthcare skills results in the poor diagnosis of mental disorders. It is important to put in place structures and the necessary plans to make sure the competence of professionals at this level of care is up to date with modern trends to aid in effective patient care. Professional training and continuous education programs may help to achieve this and make specialised skills available at a primary care level $[26,27]$. This study's results are also in line with a study which showed that public sector nurses had negative perceptions about the integration of mental health care into HIV services [28].

In this study we also found out that the most experienced mental health care professionals had more positive perceptions (Mean $=24.67 \pm 1.95),(P<0.05)$. With regards to years of service working in HIV services, participants who had $\leq 5$ years of experience had the most positive perceptions (Mean = $19.10 \pm 5.06),(p<0.05)$. While those who had worked as primary health care professional for $\geq 15$ years had the most positive perceptions (Mean $=21.11 \pm 4.15)$, $(p<0.05)$. Based on profession, it was observed that medical doctors had the most positive perception levels (Mean $=22.61 \pm$ 2.15), $(p<0.05)$.

Results obtained from the participants with regards to their perceptions of implementation of integrating mental care into HIV services at primary health care settings showed that most of health care professionals believe that, if properly managed, patients with mental ailments could fully recover and live a normal life. This can be seen from the responses to the question, "People with mental health problems can never recover fully to live a quality life", a good number of the participants did not think so, and $62.5 \%$ disagreed. It was observed that some of the participants, about $35 \%$, had a negative attitude towards mentally ill patients as the think people with mental health problems are dangerous. This negative perception by health professionals may be due to the observation or belief by most people that mental disorders are always associated with behavioural disturbances and mentally ill persons are difficult to handle [29].

There were divergent views on the integration of mental into HIV services when professionals were asked the question, "Integration of mental health into HIV services can pose a danger to me". Some of the participants don't think it will be of any danger (about $57.5 \%$ ), but the remaining participants in the study believed it was dangerous to integrate mental care into HIV services. In a study conducted in 2014, it was established that health care providers had some negative conceptions about mental care patients with regards to them being violent [30]. These authors went further to say how medical professionals view mentally disabled patients has a huge role to play on patient management and treatment outcomes [30]. Due to negative perceptions and misinformation about mental ailments, even health care practitioners do not feel comfortable attending to mentally ill patients. This may not be far from the fact that health systems, for a long time, have separated mental care from other services [31]. The results reveal that most of the participants, about $55 \%$, do not support mental care being isolated, but still some participants think mental care should be isolated. The perception of some medical professionals is that psychiatric problems may prevent mentally disturbed patients from understanding issues relating to sexuality [32]. In our study we observed that about $52.5 \%$ of participants think it is not a waste of time to treat people with mental challenges in HIV treatment facilities. 
Citation: Cele WB, Mhlongo EM (2021) Attitudes and Perceptions of Health Care Practitioners Towards the Implementation of Integrating Mental Care into HIV Services At Primary Health Care Settings. J Healthcare 4(1):70-76

It was further observed in our study that majority of the enrolled participants, about $72.5 \%$, believe they have a responsibility to intervene with people who have mental challenges. Health care professionals should consider the health of their patients a priority and, therefore, develop the needed skills and competencies to handle all the health care needs of patients. This will be of great support to global initiatives regarding mental health intervention [4].

In conclusion, there is need to implement the integration of mental health care into HIV services at a primary health care level since this is the first point of call for most patients. Also, this is important as the effective management of mentally challenged, HIV infected patients will help improve adherence to treatments. Implementing the integration of mental health care into HIV services will help provide holistic care and make available the needed facilities to ease service delivery. From our study's results, participant's attitudes towards implementing the integration of mental health care into HIV services is quite encouraging, but the perception level is low. There is need for the training of health care professionals at a primary health care level on mental health care service delivery. When health care workers are competent enough to handle the medical needs of patients, their attitude and perception level will be boosted.

\section{Acknowledgement}

Authors would like to acknowledge and thank all the participants who agreed to participate on the study. Thank the University of KwaZulu-Natal by allowing us to conduct this study. Thank the Department of Health in KwaZulu-Natal by giving us an opportunity to use their facilities during data collection process.

\section{Declaration of Interest}

The author had no competing interest with anyone.

\section{Synopsis of the Article}

This article reported on attitudes and perceptions of health care practitioners towards the Implementation of Integrating mental mare into HIV Services at primary health care settings. The researcher used a descriptive quantitative design in this study. The researcher was guided by a pragmatic approach to the study. Action research was employed in this study and findings from cycle one and two during data collection process guided this study further on identifying and diagnosing the gaps and problems that causes negative attitudes and perceptions of health practitioners towards integrating mental health into HIV services at primary health care settings. A structured questionnaire comprising of 24 items and five point Likert response scale. Majority $(72.5 \%)$ of health practitioners expressed negative perceptions towards the implementation of mental health care integration into HIV services. There was little confidence in health practitioner ability to screen and manage, mental illness.

The study findings show that the most experienced mental health care professionals, participants with experience of 5 years and less, those that have worked in primary health care for 15 years or more and medical doctors had the most positive perceptions towards providing integrated care for patients presenting with both mental health problems and HIV. Lack of knowledge and the presence of psychiatric stigma lead $62.5 \%$ of participants to feel that people living with mental health problems could never fully recover to live a quality life and $35 \%$ to believe that mental health patients were violent and/or dangerous. Training and skills development is an essential component in ensuring that programmes are implemented and integrated efficiently and successfully. There is a significant need for the provision of integrated acre at the primary level since this is the first point of health care access for most patients.

\section{References}

1. Moussavi S, Chatterji S, Verdes E, et al. (2007) Depression, chronic diseases, and decrements in health: Results from the world health surveys. Lancet 370: 851-858.

2. Patel V, Belkin GS, Chockalingam A, et al. (2013) Grand challenges: Integrating mental health services into priority health care platforms. PLoS Med 10: e1001448.

3. Collins PY, Holman AR, Freeman MC, et al. (2006) What is the relevance of mental health to HIV/AIDS care and treatment programs in developing countries? A systematic review. AIDS 20: 1571.

4. Freeman MC, Patel V, Collins PY, et al. (2005) Integrating mental health in global initiatives for HIV/AIDS. Br J Psychiatry 187: 1-3.

5. Carvalhal A (2015) Integrating mental health care for people living with HIV. Health Care Current Reviews 3: 1.

6. Bing EG, Burnam MA, Longshore $D$, et al. (2001) Psychiatric disorders and drug use among human immunodeficiency virusinfected adults in the United States. Arch Gen Psychiatry 58: 721-728.

7. Modula MJ, Ramukumba MM (2018) Nurses' implementation of mental health screening among HIV infected guidelines. International Journal of Africa Nursing Sciences 8: 8-13.

8. Jonsson G, Davies N, Freeman C, et al. (2013) Management of mental health disorders in HIV-positive patients. Southern African Journal of HIV Medicine 14: 155-165.

9. Chuah FLH, Haldane VE, Cervero Liceras F, et al. (2017) Interventions and approaches to integrating HIV and mental health services: A systematic review. Health Policy Plan 32: 27-47.

10. Dubé B, Benton T, Cruess DG, et al. (2005) Neuropsychiatric manifestations of HIV infection and AIDS. Journal of Psychiatry and Neuroscience 30: 237-246.

11. Buckingham $E$, Schrage $E$, Cournos $F$ (2013) Why the treatment of mental disorders is an important component of HIV prevention among people who inject drugs. Adv Prev Med 2013: 690386.

12. Kaaya S, Eustache E, Lapidos Salaiz I, et al. (2013) Grand challenges: Improving HIV treatment outcomes by integrating interventions for co-morbid mental illness. PLoS Med 10: e1001447.

13. Petersen I, Fairall L, Bhana A, et al. (2016) Integrating mental health into chronic care in South Africa: The development of a district mental healthcare plan. Br J Psychiatry 208: s29-s39.

14. Crowley RA, Kirschner N (2015) The integration of care for mental health, substance abuse, and other behavioral health conditions into primary care: Executive summary of an American College of Physicians position paper. Ann Intern Med 163: 298-299. 
Citation: Cele WB, Mhlongo EM (2021) Attitudes and Perceptions of Health Care Practitioners Towards the Implementation of Integrating Mental Care into HIV Services At Primary Health Care Settings. J Healthcare 4(1):70-76

15. Jacob K, Sharan P, Mirza I, et al. (2007) Mental health systems in countries: Where are we now? Lancet 370: 1061-1077.

16. Semrau M, Evans Lacko S, Alem A, et al. (2015) Strengthening mental health systems in low-and middle-income countries: the Emerald programme. BMC medicine 13: 79.

17. Lund C, Kleintjes S, Kakuma R, et al. (2010) Public sector mental health systems in South Africa: Inter-provincial comparisons and policy implications. Soc Psychiatry Psychiatr Epidemiol 45: 393-404.

18. Myers B, Lund C, Lombard C, et al. (2018) Comparing dedicated and designated models of integrating mental health into chronic disease care: Study protocol for a cluster randomized controlled trial. Trials 19: 185.

19. Ardey R, Ardey R (2015) Patient perceptions and expectations from primary health-care providers in India. J Family Med Prim Care 4: 53-63.

20. Joska JA, Sorsdahl K (2012) Integrating mental health into general health care: Lessons from HIV. Afr J Psychiatry (Johannesbg) 15: 420-423.

21. Abera M, Tesfaye M, Belachew T, et al. (2014) Perceived challenges and opportunities arising from integration of mental health into primary care: A cross-sectional survey of primary health care workers in south-west Ethiopia. BMC Health Serv Res 14: 113.

22. Mall S, Sorsdahl K, Swartz L, et al. (2012) "I understand just a little..." Perspectives of HIV/AIDS service providers in South Africa of providing mental health care for people living with HIV/AIDS. AIDS Care 24: 319-323.

23. Funk M, Saraceno B, Drew N, et al. (2008) Integrating mental health into primary healthcare. Ment Health Fam Med 5: 5-8.
24. Mugisha J, Abdulmalik J, Hanlon C, et al. (2017) Health systems context (s) for integrating mental health into primary health care in six Emerald countries: A situation analysis. International journal of mental health systems 11: 7.

25. Saraceno B, Saxena S (2002) Mental health resources in the world: Results from project atlas of the WHO. World Psychiatry 1: 40-44.

26. Do AN, Rosenberg ES, Sullivan PS, et al. (2014) Excess burden of depression among HIV-infected persons receiving medical care in the United States: Data from the medical monitoring project and the behavioral risk factor surveillance system. PLoS One 9: e92842.

27. Uebel K, Guise A, Georgeu D, et al. (2013) Integrating HIV care into nurse-led primary health care services in South Africa: A synthesis of three linked qualitative studies. BMC Health Serv Res 13: 171.

28. Dirwayi NP (2002) Mental illness in primary health care: A study to investigate nurse's knowledge of mental illness and attitudes of nurses toward the mentally ill. University of Cape Town.

29. Yeo SG, Parker G, Mahendran R, et al. (2001) Mental health literacy survey of psychiatrically and generally trained nurses employed in a Singapore psychiatric hospital. Int J Nurs Pract 7: 414-421.

30. Stuber JP, Rocha A, Christian A, et al. (2014) Conceptions of mental illness: Attitudes of mental health professionals and the general public. Psychiatr Serv 65: 490-497.

31. Swartz L, MacGregor H (2002) Integrating services, marginalizing patients: Psychiatric patients and primary health care in South Africa. Transcultural Psychiatry 39: 155-172.

32. Collins PY (2006) Challenges to HIV prevention in psychiatric settings: Perceptions of South African mental health care providers. Social Science \& Medicine 63: 979-990. 